\title{
HISTÓRIA E VIDA: O ENCONTRO EPISTEMOLÓGICO ENTRE DIDÁTICA DA HISTÓRIA E EDUCAÇÃO HISTÓRICA ${ }^{1}$
}

\section{HISTORY AND LIFE: THE EPISTEMOLOGICAL MEETING BETWEEN DIDATIC OF HISTORY AND HISTORY EDUCATION}

Ronaldo Cardoso Alves ${ }^{2}$

\begin{abstract}
RESUMO: O artigo faz um breve histórico acerca da formação do campo científico da Didática da História na Alemanha, bem como da History Education na Inglaterra e o encontro epistemológico dessas vertentes, ocorrido no início do século XXI. Num segundo momento, parte desta epistemologia para relacionar o conhecimento histórico, cientificamente concebido, às necessidades de orientação dos seres humanos no cotidiano da Cultura Histórica contemporânea. Finalmente, apresenta tal encontro como fornecedor de um repertório teórico-metodológico que possibilita a qualificação das pesquisas de Ensino de História no Brasil, com vistas à investigação a respeito da escola como lugar de desenvolvimento da consciência histórica de estudantes e professores.
\end{abstract}

Palavras-chave: Consciência Histórica. Didática da História. Filosofia da História. Educação Histórica. Cultura Histórica.

\begin{abstract}
The article gives a brief history about the formation of the scientific field of Didactic of History in Germany, as well as History Education in England and his epistemological meeting, occurred early in this century. Secondly, part of epistemology to relate historical knowledge, scientifically designed, the guidance needs of humans in quotidian Contemporary Historical Culture. Finally, it presents such a meeting as a supplier of a theoretical-methodological repertoire that enables the qualification of research Teaching of History in Brazil, aiming to research about the school as a place of development of historical consciousness of students and teachers
\end{abstract}

Keywords: Historical Consciousness. Didactic of History. Philosophy of History. History Education. History Culture.

\footnotetext{
${ }^{1} \mathrm{O}$ artigo é fruto de pesquisa com financiamento pela CAPES (Coordenação de Aperfeiçoamento de Pessoal de Nível Superior - Ministério da Educação do Brasil).

2 Professor da UNESP - Assis. Doutorado em Educação USP.
} 
De sua parte, a arte do historiador colabora com a imensa influência exercida sobre a opinião dos seres humanos, uma vez que estes não somente medem a realidade a partir de suas ideias, mas também Ihe exigem que se conforme ou reajuste a esta ou aquela maneira - e os homens o exigirão com impaciência cada vez maior o quanto mais facilmente estiverem habituados a pensar a partir da inversão de tais coisas.

Johann Gustav Droysen ${ }^{3}$

Em uma viagem ao exterior, visitei um museu situado num dos países membros da antiga "cortina de ferro" que apresentava em sua divulgação o objetivo de mostrar as dominações nazista e comunista vivenciadas pela população durante o século $X X$. Logo na entrada deparei-me com um pequeno monumento bipartido que apresentava simbologias características das duas dominações de igual maneira, mas ao percorrer os andares da exposição fiquei surpreso: percebi que a dominação soviética era retratada com incrível detalhamento e didatismo enquanto que a dominação nazista, nos poucos espaços reservados em três andares da exposição, nem de longe reproduzia a intensidade e minúcia retratadas do domínio soviético. Depois da visita comecei a levantar hipóteses a respeito do que havia presenciado: será que havia algo ideológico naquela opção?; ou a intensidade da dominação teria sido diferente (se é que esse tipo de situação, para quem sofre, possa ser mensurável)?; ou o fato da dominação soviética ter ocorrido posteriormente à nazista de alguma forma eliminou os vestígios históricos da invasão alemã e, por isso, não havia como apresentá-los de igual maneira? Essas e tantas outras hipóteses poderiam ser levantadas. Ao pesquisar posteriormente o assunto, verifiquei que o museu, quando de sua inauguração e invariavelmente, tem sido elogiado por apresentar detalhadamente o domínio soviético, mas acusado de omissão pela superficialidade com a qual mostrou o domínio nazista. Para os críticos, tal opção teria um fundo ideológico.

Numa outra experiência, há alguns anos, agora em sala de aula, discutia um mesmo assunto - o processo de escravidão no Brasil - em dois contextos distintos da Cidade de São Paulo: numa escola privada, composta por alunos

\footnotetext{
3 - DROYSEN, J. G. Arte e Método (1868). In. MARTINS, Estevão de R. (Org.). História pensada: teoria e método na historiografia europeia do Século XIX. Tradução de Pedro S. P. Caldas. São Paulo: Contexto, 2010, p. 40.
} 
pertencentes à denominada classe socioeconômica média-alta, e numa escola pública, situada num bairro periférico, composta por alunos moradores da região, pertencentes a famílias de baixa renda. Em ambos os casos existia, de maneira geral, a compreensão por parte dos alunos de que a escravidão foi um processo terrível para indígenas, africanos e seus descendentes e teve implicações fundamentais no processo histórico brasileiro. No entanto, ao solicitar aos alunos que refletissem a respeito da relação desse conteúdo histórico com o contexto histórico brasileiro contemporâneo, algo interessante ocorreu: nos dois espaços a questão da escravidão foi relacionada à discussão em torno da adoção de cotas raciais por universidades públicas no Brasil. Enquanto boa parte dos alunos da sala de aula da escola privada criticava tal política, utilizando como justificativa uma matéria jornalística oriunda da revista semanal de maior circulação do país (que tecia críticas ferozes à adoção dessa prática), a maior parte dos alunos da sala de aula da escola pública, defendia a medida, dizendo que a desigualdade social vivenciada em seu cotidiano por si só já a justificava. Uma questão polêmica que, obviamente, não era consenso sequer entre os alunos de cada espaço: existiam também aqueles que defendiam posicionamentos distintos dos que foram apresentados com maior ênfase em sala de aula. Mas o fator que chamou a atenção nesse contexto foi a diferença de aplicação da discussão derivada da História para a vida prática. Ambos partiram do mesmo conteúdo histórico, mas ao estabelecerem relações utilizaram diferentes aspectos de seu cotidiano para justificarem sua argumentação. A experiência humana trazida à memória na aula de História foi interpretada a partir dos interesses de cada grupo em gerar respostas às questões de seu contexto vital.

Esses exemplos mostram a importância da reflexão histórica para a vida prática. A relação entre o conteúdo histórico estudado, as fontes utilizadas para justificativa dos posicionamentos, as propostas de orientação e os aspectos identitários constituídos revelam aspectos importantes referentes à construção da consciência histórica na contemporaneidade. Situações como essas se reproduzem diariamente em aulas de História, em museus, filmes, novelas, matérias jornalísticas ou mesmo na conversa com os pais, avós ou amigos, e constituem fonte importante de reflexão acerca da necessidade de mobilização do pensamento histórico para a orientação humana. 
As pessoas cotidianamente utilizam-se da rememoração de acontecimentos do passado individual ou coletivo com vistas a comprovar ou rejeitar ideias, justificar posicionamentos, criar concepções. A relação entre os feitos da trajetória humana no tempo e as diferentes formas com as quais esse percurso foi contado, transmitido e retransmitido ao longo das gerações constitui a base do pensar historicamente. Dessa digressão surge a pergunta: será que ao estudarmos História em espaços escolares ou extraescolares conseguimos perceber a profunda relação que ela tem com nossa própria vida?

O excerto de Droysen na epígrafe deste texto apresenta a relação dialógica entre $o$ ato de construir o conhecimento histórico científico e as necessidades de orientação dos seres humanos em seu cotidiano. Entre essas duas ações se encontram desafios enfrentados pela História desde a época de sua concepção, enquanto área do saber científico, até os dias atuais, como, por exemplo: que parâmetros metodológicos são eficazes para dotar a História de plausibilidade e fiabilidade para as questões do cotidiano contemporâneo? Como possibilitar às diferentes gerações habilidades e competências cognitivas oriundas da ciência da História que proporcionem sentido às decisões da vida?

Droysen, um dos principais expoentes do historicismo alemão do século XIX, defendia que a linguagem histórica deveria chegar à população de forma palatável, não enfadonha, e concomitantemente, teria de contemplar um grau de cientificismo que outorgasse credibilidade ao narrado. $O$ cientificismo não anularia o didatismo, pois a História deveria ser credível e compreensível. Uma síntese entre o que chamava de "ato artístico" do pensar humano e o método com o qual tal "arte" seria exercida. (DROYSEN, 2010, p.41)

O conceito de arte discutido por Droysen remete a uma espécie de superávit de humanização que subjaz ao ato de pensar e fazer História. Se nas ciências ditas empíricas a objetividade obedece a limites impostos pelo rigor do método e pela demanda antecipadamente colocada pelo objeto de estudo, na ciência histórica a arte reside na relação entre a objetividade (do trabalho metodológico junto às fontes) e a subjetividade (do ato interpretativo do pesquisador). Subjetividade e objetividade, entremeadas, constituiriam o ato artístico e metodológico de fazer (e viver) História. Num momento histórico em que as ciências naturais apuravam seus métodos para dotar os resultados de 
suas pesquisas da maior objetividade possível, as ciências humanas sofriam dessa carência ao serem avaliadas por parâmetros fundamentados em premissas que não consideravam a dicotomia existente entre a subjetividade e objetividade do pensamento. É nessa perspectiva que emerge a importância da Teoria da História. Para Droysen é a teoria que clarifica as semelhanças e diferenças entre a metodologia utilizada para construir a História (como ciência) e a própria História vivida:

Todos os métodos [...] que encontram aplicação na área de estudos históricos, movimentam-se dentro da mesma periferia, têm o mesmo ponto de gravitação determinante. Sintetizá-los em pensamentos comuns, desenvolver seu sistema e sua teoria e assim determinar as leis da pesquisa histórica, e não leis da história: essa é de fato a tarefa da teoria da história. (DROYSEN, 2010, p. 46)

História (como ciência) e vida (prática) sempre estiveram relacionadas, seja no âmbito dos interesses de satisfação das carências de orientação da sociedade, seja na necessidade do estabelecimento de parâmetros que possibilitem fiabilidade às narrativas geradas para representarem essa mesma ação temporal dos seres humanos. É nesse contexto que emerge o desafio de compreender as pretensões da racionalidade do pensamento histórico:

[...] ela [a ciência da História] emerge de uma inegável carência profunda de todos os homens que agem e sofrem as consequências das ações dos outros, de orientar-se em meio às mudanças que experimentaram em seu mundo e de si mesmos. A ciência é desafiada por essa carência, cuja evidência ela não tem muito como negar, por dois motivos: de um lado, a ciência é (ao menos no que ela diz de si mesma) um produto aracional do tratamento da história; de outro lado, a reflexão humana sobre a história (inclusive na ciência da história) tem por finalidade obter um conhecimento histórico com o qual se pode situar qualquer um no processo do tempo. (RÜSEN, 2001, p.12)

Nesse sentido, é fundamental refletir a respeito da relação entre o trabalho historiográfico do especialista e a recepção, compreensão e utilização desse material por parte da sociedade em sua intrínseca relação com as contingências do tempo. Em outras palavras, se se pensa na relação existente entre o trabalho do historiador, o aprendizado histórico e seus usos históricos políticos e sociais, imprescindível é a existência de uma teoria que pretenda pensar o pensamento 
histórico por meio da racionalidade que nela está subsumida. É esse exercício metateórico que aproxima a ciência da História da vida prática:

[...] o pensamento é um processo genérico e habitual da vida humana. A ciência é um modo particular de realizar esse processo genérico e habitual na vida humana. A ciência é um modo particular de realizar esse processo. O homem não pensa porque a ciência existe, mas ele faz ciência porque pensa. Se se puder estabelecer que esse modo particular, científico, do pensamento histórico está enraizado no pensamento humano em geral, ter-se-á um ponto de partida para responder à pergunta: por que o pensamento se dá e se deve dar no modo científico? (RÜSEN, 2001, p.54)

O excerto acima revela a preocupação de aproximar a cientificidade da História às necessidades cotidianas dos seres humanos. Para o autor contemporâneo Jörn Rüsen, é exatamente essa relação intrínseca entre História e Vida que deve nortear o labor historiográfico sem o qual não haveria sentido construir racionalmente o conhecimento histórico. Essa asserção do autor alemão não é fortuita. Nela subjaz a ideia de que o raciocínio histórico é fundamental para dotar os seres humanos de instrumentos cognitivos estruturados com o fim de enfrentar, conscientemente, a rotineira tomada de decisões demandadas de uma cultura histórica na qual ocorre a multiplicidade e diversidade da informação.

É interessante observar a preocupação desses autores alemães, separados por um século, em relacionar História e Vida no contexto do aprendizado histórico na Alemanha. Tal relação não é nova e não se limita ao contexto germânico. É anterior ao surgimento da História como disciplina acadêmica no mundo ocidental. Até as últimas décadas do século XVIII, antes do processo de cientificização moderna da História, inaugurada com a criação de sua metodologia de pesquisa, o labor historiográfico se pautava por demandas de aprendizagem na sociedade ocidental. A transmissão da memória às futuras gerações e, consequentemente, a construção do conhecimento histórico nos mais diferentes espaços - desde as ruas da acrópole ateniense, passando pelas estradas romanas e feudos medievais, até os casebres dos trabalhadores na urbanização das cidades europeias - seguia a máxima ciceroniana da Historia 
Magistra Vitae ("História Mestra da Vida") e revelava que o ensino e a aprendizagem, dispersos na sociedade, compunham sua cultura histórica. ${ }^{4}$

Com o processo de cientificização da História, inaugurada pelo Iluminismo, a formação do pensamento histórico e, consequentemente, a construção da consciência histórica, saiu do espaço público e adentrou paulatinamente ao espaço privado à medida que se vinculou ao trabalho metodológico criado e partilhado por especialistas desse tipo de conhecimento. O ato de ensinar, de transmitir a História às novas gerações - a denominada Didática da História sofreu uma espécie de assepsia, pois deixou uma função estruturante na aprendizagem histórica (mesmo limitada à reprodução de um conjunto de memórias do cotidiano prático das pessoas) e se tornou conjuntural (até mesmo marginal) à medida que Ihe foi destinada a pragmática função de treinar professores que simplesmente deveriam transformar saber histórico acadêmico em saber histórico escolar. Nesse sentido, a Didática da História passou a ser meramente

[...] uma disciplina que faz a mediação entre a história como disciplina acadêmica e o aprendizado histórico e a educação escolar. Assim, ela não tem nada a ver com o trabalho dos historiadores em sua própria disciplina. A didática da história, sob essa visão, serve como uma ferramenta que transporta conhecimento histórico dos recipientes cheios de pesquisa acadêmica para as cabeças vazias dos alunos. (RÜSEN, 2010, p.23)

A cientifização da História que poderia aprofundar sua aproximação à Vida, por meio da sistematização do pensamento histórico, utilizou esse atributo para dela se distanciar. Na busca de sua legitimação como disciplina do conhecimento científico, a História (criticada até então por estar a serviço da reprodução de tradições e modelos culturais), teve como resultado uma autorreflexão limitada estritamente vinculada à sua própria empiria e metodologia. A prevalência do caráter metodológico, portanto, não resultou numa autorreflexão individual e coletiva, ou seja, na autonomia de construção e desenvolvimento da consciência

\footnotetext{
${ }^{4}$ - A concepção ciceroniana de História como uma coleção de eventos exemplares que norteiam a consciência histórica da sociedade, ou seja, como fornecedora de modelos culturais prescritores e preestabelecidos, é trabalhada no artigo de Reinhart Koselleck Historia Magistra Vitae, que é parte da obra traduzida para o português: KOSELLECK, R. Futuro Passado: contribuição à semântica dos tempos históricos. Tradução de Wilma Patrícia Maas e Carlos Almeida Pereira; Revisão de César Benjamin. Rio de Janeiro: Contraponto \& Ed. PUC-Rio, 2006.
} 
histórica. Abriu espaço para a legitimação ideológica que encontrou morada na consciência histórica das sociedades ocidentais à medida que suas demandas de orientação temporal e constituição identitária foram estabelecidas por grupos políticos dirigentes dos Estados e, posteriormente, na segunda metade do século $X X$, também por interesses privados de conglomerados econômicos. O lema positivista impresso na bandeira brasileira tem muito a dizer sobre isso. 0 progresso era decorrente da ordem. Se se pensar na construção da consciência histórica, tal ordenação do pensamento era estabelecida por quem dominava sua metodologia.

Uma Didática da História com tais prerrogativas como as demonstradas acima, só poderia cumprir a função de reprodução irrefletida do conhecimento nos bancos escolares. Aos alunos caberia apenas reproduzir a História ideologicamente concebida com vistas à manutenção no poder dos grupos políticos desejosos de ali continuarem arraigados - algo que Rüsen (2007, p.89) chama de "Didática da Cópia". Os Estados nacionais modernos, os regimes totalitários, as ditaduras de diversas correntes ideológicas se apoiaram nesse tipo de construção do conhecimento histórico a fim de transmitir, expandir e perpetuar a ideologia de seu pensamento formando uma mentalidade pública obediente às suas convicções.

Assim, a aprendizagem histórica que surgira no âmbito público na Antiguidade, ainda que freado em seu caráter reflexivo, teve na proeminência de seu método, o fortalecimento de sua instrumentalidade com o fim de dominação e legitimação ideológica. Narrativas historiográficas ideológicas eram transpostas como saber aos alunos nas escolas e estes, por sua vez, eram alijados de qualquer possibilidade de compreensão desses mesmos instrumentos de reflexão metodológica da História. Se a Didática da História deixou de ter um caráter público devido ao controle metodológico da História por parte dos especialistas, somente a publicização desses mesmos instrumentos empíricos e metodológicos, mediadas por uma reflexão didática, poderia ressuscitar o caráter público da Didática da História.

Nos últimos quarenta anos, o campo da metodologia do ensino de História tem procurado com maior consistência empírica e epistemológica, concertar caminhos que provejam à disciplina de História elementos que a caracterizam 
como fundamental para o desenvolvimento da consciência histórica nos indivíduos, com vistas à sua utilização na vida cotidiana. Em outras palavras, essas vertentes partiram da premissa da necessidade de constituir parâmetros claros que respondam à pragmática pergunta que rotineiramente se apresenta no cotidiano intra e extraescolar: afinal, para que serve a História? Tal pergunta, por si só, já revela a necessidade de transformar a realidade instrumental ideológica da História em um instrumento de autorreflexão pública que permita às pessoas e aos grupos da sociedade construir identidade e se colocar autonomamente diante dos problemas de orientação temporal (im)postos pelo cotidiano.

Foi nesse contexto que emergiu uma nova concepção da área de estudo denominada Didática da História na Alemanha e esta diretamente tem influenciado pesquisas brasileiras do campo do ensino de História. Dentre variadas linhas de estudo destaca-se o trabalho do já citado Jörn Rüsen, o qual parte de referenciais epistemológicos que têm como premissa relacionar a produção historiográfica oriunda da ciência da História com a Vida prática dos indivíduos na sociedade. Essa relação tem na formação histórica seu objetivo, a qual ocorre por meio de uma modificação estrutural nos princípios de aprendizagem histórica. Ao elaborar sua matriz disciplinar relacionando o tripé Filosofia da História, Ciência da História e Vida Prática, sob a mediação da Razão Histórica, Rüsen se coloca como importante referencial epistemológico da Didática da História e, praticamente, tem sido citação obrigatória na maior parte das publicações do campo, devido à amplitude de suas propostas:

[...] as perspectivas da didática da história foram grandemente expandidas, indo além de considerar apenas os problemas de ensino e aprendizado na escola. A didática da história analisa agora todas as formas e funções do raciocínio e conhecimento histórico na vida cotidiana, prática. Isso inclui o papel da história na opinião publica e as representações nos meios de comunicação de massa; ela considera as possibilidades e limites das representações históricas visuais em museus e explora diversos campos onde os historiadores equipados com essa visão podem trabalhar. (RÜSEN, 2010, p. 32-3)

A sucessão dos trabalhos desse autor alemão revela sua preocupação em discutir a ideia de que há uma necessidade de pensar historicamente comum a 
todos os seres humanos e, consequentemente, operações mentais cognitivas constitutivas que Ihes são comuns, independentemente da cultura histórica da qual provenha. Obviamente uma leitura simplista e descontextualizada dessa última frase pode levar à compreensão de que se trata de uma teoria de caráter reducionista e hermético. É exatamente o oposto. Rüsen é um pensador eclético que enfrenta a desafiadora tarefa de dialogar com diferentes correntes historiográficas concebidas no Ocidente e, concomitantemente, "costurar" caminhos de diálogo entre a historiografia do Ocidente e do Oriente ${ }^{\mathbf{5}}$. Seu objetivo: construir parâmetros que sejam comuns com vistas a dotar de sentido a racionalidade histórica.

Se comprovadamente o trabalho de Rüsen tem um caráter inovador por investir, obstinadamente, na racionalização de sentido da consciência histórica relacionando Ciência da História e Vida cotidiana, é verdade também que existe um grande espaço a ser preenchido por pesquisas empíricas, sobretudo nos espaços escolares, que apliquem as concepções dessa vertente teórica na própria Alemanha. Destaca-se nesse contexto o trabalho de pesquisadores como Bodo von Borries e M. Angvik que coordenaram, entre outras pesquisas, o projeto Youth and History (1997) ${ }^{6}$, que abarcou alguns professores e cerca de trinta mil jovens de vários países europeus, com idade média de quinze anos. Pesquisa que teve como principal resultado o fato de apresentar um mapeamento geral das ideias históricas dos alunos, sobretudo concernentes à relação entre evidências e temporalidade históricas. No entanto, não aprofundou-se no que concerne à aplicação prática das operações mentais do pensamento histórico na orientação temporal dos jovens em seu cotidiano. Coube a outras vertentes dos estudos da cognição histórica na Europa a se ocuparem dessa demanda, mesmo sem ter uma relação direta inicial com a pesquisa alemã.

Partindo da necessidade de fortalecer o ensino de História na GrãBretanha e legitimar esse campo específico do conhecimento, pesquisadores

\footnotetext{
${ }^{5}$ Em relação a aproximações entre historiografias de diferentes culturas, consultar RÜSEN, J. Theoretical Approaches to an Intercultural Comparison of Historiography. In. History: narration interpretation - orientation. Making Sense of History. Vol.2. Oxford: Berghahn Books, 2005, p.109-128 ou sua tradução em RÜSEN. J. Historiografia Comparativa Intercultural. Tradução de Jurandir Malerba. In. MALERBA, J. (Org). A História Escrita. São Paulo: Editora Contexto, 2006, p. $115-137$.

${ }^{6}$ ANGVIK. M.; BORRIES, B. Youth and History: a comparative European survey on historical and political attitudes among Adolescents. Hamburg: Korber Foundation, 1997.
} 
como Dennis Shemilt, Peter Lee, Alaric Dickinson e Rosalyn Ashby, concentraram seus esforços em estudos a respeito da possibilidade de progressão do pensamento histórico nos alunos. O primeiro movimento dessa vertente ocorreu ainda nos anos 1960, com o trabalho de Shemilt que coordenou a última fase do "Projeto 13-16". Nesse projeto, desenvolveu-se a utilização de ferramentas do trabalho historiográfico junto a pequenos grupos de professores e alunos (com idade entre 13 e 16 anos) com o fim de modificar a forma pela qual a História era ensinada nas escolas britânicas. Um terço das escolas britânicas aderiu rapidamente ao projeto e seus resultados tiveram tamanha repercussão no país anglo-saxão, que o currículo de História passou por substancial modificação, como narra Peter Lee:

\begin{abstract}
Uma das razões pelas quais as pessoas mudaram foi constatar que anteriormente, as crianças encaravam a História como maçadora e inútil e os pais também a achavam assim; com o Projecto, as crianças passaram a olhar para a História como uma disciplina interessante, difícil como a matemática, mas sem quererem desistir dela. Com efeito, um dos objetivos do Projecto era fazer da História uma disciplina séria. Era necessário haver algo que as crianças aprendessem progressivamente, que se operassem mudanças de ideias e que elas conseguissem perceber essas mudanças. De facto, as crianças relacionavam melhor as suas ideias em História. (LEE, 2001, p. 14)
\end{abstract}

A mudança de paradigma proporcionada pelo novo olhar para o ensino de História no Reinou Unido permitiu o aprofundamento e ampliação das pesquisas nas décadas posteriores. O Projeto Chata (1996), desenvolvido junto a um grupo de alunos com idade variando entre seis e quatorze anos, sob a coordenação dos pesquisadores Peter Lee, Alaric Dickinson e Rosalyn Ashby ${ }^{7}$ teve como objetivo estudar a ocorrência de progressividade no pensamento histórico dos alunos através da análise de narrativas construídas a partir da investigação de fontes históricas imagéticas e escritas. Baseados em pressupostos epistemológicos oriundos, inicialmente, da Filosofia da História anglo-saxã, esses pesquisadores construíram uma metodologia que privilegiava a análise de dados seguindo um modelo conceitual envolvendo diferentes níveis de compreensão, explicação,

\footnotetext{
7 ASHBY, R.; DICKINSON, A.; LEE, P.; Project Chata: concepts of History and Teaching Approaches at key stages 2 and 3. Teaching History, 82, 1996, p. 6-30.
} 
interpretação de fontes e percepção crítica de diversas narrativas históricas. Tal modelo conceitual foi constituído por parâmetros analíticos que levaram à conclusão de que a progressão do pensamento histórico dos alunos não está diretamente vinculada à idade ou seriação escolar. Antes, é determinada pelo adquirir de habilidades metodológicas que permitem a maturação do raciocínio histórico na avaliação de evidências que comprovem suas interpretações a respeito de uma determinada demanda histórica.

Surgiu, assim, a denominada History Education (Educação Histórica) que hoje é reconhecidamente campo do conhecimento no Reino Unido e tem se espalhado com essa denominação no mundo, inclusive no Brasil. Tais pesquisas trazem importante contribuição ao estudo da formação do pensamento histórico nos indivíduos à medida que apontam caminhos de construção de instrumentos de pesquisa e levam em consideração habilidades a serem desenvolvidas pelos alunos no tocante à sua relação com a pluralidade narrativa histórica. Além disso, apresentam a proposta inovadora de utilizar princípios da racionalidade do método histórico de investigação, antes reduzida aos especialistas oriundos dos bancos acadêmicos, para a formação histórica dos alunos nos bancos escolares do ensino básico e secundário. Essa proposta tornou-se uma alternativa dinâmica e opositora a um ensino sem reflexão e depositário de ideologias, portanto, enfrentadora de algo semelhante à demanda da Didática da História na Alemanha.

Dessa forma conclui-se que, por meio de um percurso totalmente diferente da vertente alemã, a Educação Histórica também recusou a dicotomia entre os denominados saber escolar e saber científico. De um lado, a Didática da História alemã parte da racionalidade histórica, estruturada principalmente no espaço escolar, que relaciona a História às necessidades da vida cotidiana com a finalidade de construir consciência histórica. Do outro lado, a Educação Histórica anglo-saxã, toma a vivência escolar como ponto de partida para a construção do conhecimento histórico, mediada por uma reflexão epistemológica construtora de metodologias que dotem alunos e professores de habilidades e competências históricas que os façam ler e agir no mundo que os cerca. Com demandas e objetivos comuns, mas percursos históricos diferentes, 0 encontro 
epistemológico entre essas diferentes linhas do ensino de História seria uma questão de tempo.

Num contexto histórico no qual a História tem passado por constantes questionamentos de seu caráter de cientificidade (nos seus aspectos teóricos e metodológicos) e enquanto disciplina (ao perder espaço, em alguns países, em currículos que têm privilegiado uma fusão com a Geografia e/ou outras ciências humanas ou mesmo para uma pseudo-disciplina denominada "Cidadania", onde tudo e nada cabem ao mesmo tempo), o fortalecimento do campo do Ensino de História, em todas as suas vertentes, se reveste de um caráter singular. Diante desse quadro, o intercâmbio de pesquisas dessas diferentes correntes do Ensino de História, ocorrida a partir do início do presente século, tem sido de vital importância para o reconhecimento e legitimação, inclusive política, desse campo do conhecimento científico na Educação. Essa espécie de encontro epistemológico entre os estudos oriundos da Filosofia da História alemã (na qual está inserida a Didática da História) e o trabalho empírico-epistemológico dos pesquisadores da Educação Histórica anglo-saxã ${ }^{8}$, tem proporcionado uma série de benefícios para a pesquisa em Ensino de História, inclusive no Brasil.

O que se pretende com a utilização da Filosofia da História na construção da base epistemológica do Ensino de História não é a transformação dos alunos do ensino básico e secundário em pequenos historiadores. Almeja-se, sim, refletir acerca de possibilidades, racionalmente constituídas, de práticas metodológicas que visem desenvolver as operações mentais do pensamento histórico, seja em seu aspecto substantivado (na compreensão e aplicação dos conceitos históricos na vida prática), seja em sua vertente meta-histórica (concernente aos instrumentos cognitivos utilizados para raciocinar historicamente). Em síntese: uma formação histórica que compreenda os estudantes não como depositários de conteúdos factuais, mas como portadores de habilidades e competências que os farão enfrentar, crítica e autonomamente, os desafios do mundo contemporâneo:

\footnotetext{
${ }^{8}$ Importante trabalho que relaciona as contribuições teóricas de Rüsen à ação teórico-metodológica da History Education inglesa se encontra na comunicação feita por Peter Lee no Annual Meeting of American Educational Research Association (Encontro Anual da Associação Americana de Pesquisa em Educação) ocorrido em New Orleans, no ano de 2002, intitulada Walking backwards into tomorrow: historical consciousness and understanding history (Caminhar para trás em direção ao amanhã: - consciência histórica e entendimento da História). Disponível na Internet na página http://centres.exeter.ac.uk/historyresource/journal7/lee.pdf. (Acesso em 12/04/2012)
} 
$\mathrm{Na}$ sociedade atual, é preciso saber seleccionar entre várias propostas e saber decidir a favor das melhores. Quando jovens e adultos são, cada vez mais, incitados pelos media a optar entre ideias ou entre produtos, a formação de uma opinião fundamentada torna-se hoje de extrema relevância. Não para que todos escolham exactamente o mesmo, mas para que o façam com critérios de alguma qualidade e rigor. A educação histórica e social poderá ter um contributo neste campo, se proporcionar aos alunos o exercício gradualmente crítico de abordagem de versões diferenciadas. Será esta - entendemos - uma das muitas formas possíveis e válidas de ajudar os jovens a apropriar-se cognitivamente do real. (BARCA, 2006, p. 23)

Nessa linha, a autora portuguesa Isabel Barca tem desenvolvido fundamental trabalho ao aprofundar epistemológica e empiricamente as premissas desse campo do conhecimento. Desde o ano de 2003, essa pesquisadora coordena o Projeto HICON ("Consciência Histórica - Teoria e Práticas"), composto por uma série de pesquisas desenvolvidas não somente em Portugal, mas também em importante intercâmbio junto ao Brasil e a outros países de fala portuguesa como Moçambique, Angola e Cabo Verde.

Barca inicialmente desenvolveu estudos acerca da provisoriedade da explicação histórica em alunos portugueses. A partir da análise das respostas a um questionário que relacionava fontes históricas a diferentes narrativas historiográficas (do ponto de vista explicativo e temporal) de uma passagem da história portuguesa, construiu um modelo que apresentou diferentes níveis de explicação provisória em História, constatando, assim, a progressividade no pensamento histórico nos estudantes. (BARCA, 2000). Seu grupo de investigação tem expandido as discussões acerca da Educação Histórica no mundo ao promover constantes intercâmbios com interlocutores da América (inclusive no Brasil), Europa, África e Ásia, o que a reveste de característica singular.

Esse importante histórico de contribuições em todo o mundo no campo do ensino de História contribuiu para o desenvolvimento de um grande número de pesquisas no Brasil $^{9}$ que relacionam a formação do pensamento histórico à sua

\footnotetext{
${ }^{9}$ No Brasil, os estudos ligados à Didática da História e Educação Histórica têm se desenvolvido em várias universidades, como, por exemplo, no CEPEDIH (Centro de Pesquisa em Didática da História) da Faculdade de Educação da Universidade de São Paulo (FE-USP), coordenado pela Profa. Dra. Katia Maria Abud, no LAPEDUH (Laboratório de Pesquisa em Educação Histórica) da Universidade Federal do Paraná (UFPR), coordenado pela Profa. Dra. Maria Auxiliadora Schmidt, no Laboratório de Ensino de História da Universidade Estadual de Londrina (LABHIS-UEL), coordenado pela Profa. Dra. Márcia Elisa Teté Ramos, dentre outros.
} 
aplicação prática no cotidiano de pessoas de diferentes realidades socioeconômicas, políticas e culturais.

Essa discussão deve partir do lugar de gênese da teoria da consciência histórica. O conceito de consciência histórica, tal como definido por Rüsen, dialoga prioritariamente (e não poderia ser diferente) com interlocutores do contexto histórico europeu. Ora, num contexto pós-queda do muro de Berlim (1989) que promoveu, paulatinamente, a abertura de um novo espaço de mobilidade socioeconômica e, consequentemente o encontro de pessoas com características que as aproximavam e, ao mesmo tempo distanciavam, foi mister o concerto de pilares epistemológicos da ciência da História que dessem conta dessa demanda da consciência histórica, ou seja, que provessem as diferentes gerações (com sua diversidade de características e memórias) de elementos que possibilitassem sua construção identitária individual e coletiva e, paralelamente, auxiliassem em sua orientação prática no tempo. Exemplo dessa necessidade se deu na própria Alemanha de Rüsen, na convivência entre habitantes das antigas partes Ocidental e Oriental que, embora tivessem a mesma identidade nacional todos são alemães - possuíram um passado histórico recente vivido em bases políticas, econômicas e até mesmo socioculturais que os distanciaram perversamente.

Esse quadro também suscitou questões à consciência histórica na medida em que existiu a necessidade de se discutir os problemas de identidade apresentados por esse processo. Se se pensar novamente no caso alemão, devese considerar que era fundamental ter consciência histórica do que havia ocorrido na região a fim de garantir, ao menos, um mecanismo de conscientização que provesse do poder de crítica a geração de alemães filhos de famílias de condições socioeconômicas tão distintas. Era necessário saber que contingências históricas determinaram a diversificação da configuração socioeconômica do país unificado. Se expandirmos esse raciocínio para a Europa, como discutir as demandas de identidade que definem o ser europeu em concomitância com o ser alemão, português, dinamarquês ou turco, se não por uma reflexão a respeito do processo histórico europeu e sua interferência em todas as suas nações? 
Mais ainda, o processo de globalização ampliou o movimento migratório das nações subdesenvolvidas economicamente para as nações desenvolvidas. No caso europeu, passados mais de vinte anos da queda do muro, gerações de famílias dos antigos países colonizados da África, Ásia e até mesmo da América construíram suas vidas em território de seus ex-colonizadores em busca de uma estabilidade que não possuíam em seus países devido à falta de infraestrutura. Soma-se a esse processo, o deslocamento de famílias inteiras vindas dos países da antiga "cortina de ferro", que sucumbiram economicamente com a derrocada do comunismo e ainda passaram (e passam) por conflitos internos de ordem civil.

A atual crise econômica que assola o mundo, resultado de um processo de globalização desregrado, modificou a paisagem humana europeia. Empregos de pouca qualificação antes desprezados pelos europeus, agora são disputados até mesmo por quem tem qualificação na ânsia de se obter alguma remuneração para dar conta das despesas mínimas de sobrevivência e de dívidas contraídas, seja para equipamentos eletrodomésticos nos lares, seja para adquirir um automóvel ou casa própria. Asiáticos se organizam no mercado formal popular, enquanto africanos constroem relativa organização no mercado informal, e muitos imigrantes do leste europeu vivem em estado de mendicância. Tal desigualdade socioeconômica também é objeto de discussão da consciência histórica - numa Europa que cada vez mais se torna uma região miscigenada com crianças de todos esses grupos étnicos estudando em suas escolas - com o intuito, entre outras coisas, de obter ferramentas para orientação no tempo e criação de identidade.

Dessa forma, ao ser aplicado num contexto não europeu como o latinoamericano, mais especificamente, o brasileiro, o conceito de consciência histórica reedita características semelhantes ao "Sitz in Leben" (contexto vital) de sua concepção na medida em que suas dimensões continentais demandam discussões acerca da identidade. Entretanto, exige também o pensar a respeito da formação de uma consciência histórica dialógica que reflita sobre as diferenças sociais de um país que, embora não tenha sofrido tanto o impacto da atual crise econômica mundial, continua a reproduzir um modelo político e socioeconômico baseado num patrimonialismo que beneficia oligarquias 
políticoeconômicas em detrimento da ampla parcela mais pobre da sociedade. Ora, num Brasil que somente na transição dos séculos XX para XXI timidamente iniciou um processo de diminuição das diferenças sociais, mas que ainda conserva a fragilidade de suas instituições democráticas pós-ditadura militar, fazse necessário pensar as questões da consciência histórica em comparação com um contexto diferenciado, para, assim, perceber suas especificidades.

Em resumidas palavras, a discussão em torno da consciência histórica na sociedade contemporânea globalizada passa pela relação que os seres humanos constroem com a Cultura Histórica da qual são participantes. define cultura histórica como

[...] o campo de interpretação do mundo e de si mesmo, pelo ser humano, no qual devem efetivar-se as operações de constituição de sentido da experiência do tempo, determinado pela consciência histórica humana [...] [em outras palavras ela é o] campo em que os potenciais de racionalidade do pensamento histórico atuam na vida prática (RÜSEN, 2007, p.21).

Dentro dessa perspectiva o conceito de cultura está umbilicalmente relacionado à História. Para Martins (2007, p.33) a "história exprime [...] a cultura dimensionada no tempo" e esta, por sua vez, se constitui como a "[...] suma da natureza racional humana, que se exprime na interdependência entre apropriação interpretativa do mundo pelo homem e afirmação da autonomia subjetiva do homem." Do encontro desse diálogo surge a cultura histórica como "[...] a articulação de percepção, interpretação, orientação e teleologia, na qual o tempo é um fator determinante da vida humana."

Pensado dessa forma, todos os seres humanos partilham de aspectos culturais convergentes e divergentes e suas ações temporais passam pelo crivo da interpretação de si mesmos e do mundo do qual fazem parte. Nesse contexto, o desenvolvimento e qualificação das operações mentais do pensamento histórico são de extrema relevância, pois possibilitam a construção de uma autonomia reflexiva que dote de sentido as opções cotidianas. Abre espaço, de igual forma, à reflexão a respeito da identidade em meio ao contexto de encontro (confronto?) cultural contemporâneo sem precedentes na História. 
A cultura histórica apresenta-se a todos os seres humanos em três distintas dimensões que se entrelaçam. O resultado desse encontro é o fornecimento de identidades, memórias, representações temporais, símbolos, ideologias e tantos outros componentes da cultura que influenciam diretamente a história de cada um. A consciência histórica atua, nesse contexto, como fornecedora de sentido às ações humanas à medida que todos se deparam com uma carga cultural que lhe precede e também prescreve tradições e modelos. Estes podem ser seguidos, questionados, relidos, transformados de acordo com a forma pela qual cada um aplica seu pensamento histórico, conscientemente, à vida.

A dimensão estética da cultura histórica se apresenta aos seres humanos em suas construções artísticas. A literatura, o teatro, o cinema, a arquitetura, as tradições populares representam aspectos da experiência humana e são portadoras de significados e sentidos. Seus autores sejam indivíduos, grupos ou instituições geram, com suas criações, formas de pensar e vivenciar o cotidiano. Aqueles que recebem essa produção cultural as percebem, interpretam, trazem à memória o que pode alimentar suas convicções de orientação na vida. A cultura histórica representa em sua dimensão estética, a beleza da produção cultural da humanidade.

A política também representa uma dimensão da cultura histórica. A legitimidade dos sistemas e organizações políticas de instituições e nações é construída historicamente, pois se alimenta das experiências humanas representadas em ações simbólicas que, trazidas à memória e interpretadas, geram significado e sentido àqueles que passam a compartilhar das concepções a elas subjacentes. Relações de poder estão em jogo na dimensão política da cultura histórica. Ao deparar-se com suas prescrições, os seres humanos podem referendá-las, rejeitá-las, aderi-las ou mesmo revolucioná-las... a consciência histórica, nesse contexto, possibilita aos seres humanos o poder de decidir a respeito da legitimidade dos discursos e ações políticas para a vida prática.

A terceira dimensão da cultura histórica que interfere diretamente na vida humana se relaciona ao conhecimento. Num mundo em que o desenvolvimento da tecnologia da informação provê à maior parte do globo acesso a incontável quantidade de informações, é fundamental criar mecanismos que gerem critérios 
de plausibilidade e credibilidade que permitam a seleção de experiências a serem interpretadas com o fim de orientação temporal. As ciências (e em nosso caso, a ciência da História) têm papel fundamental para o exercício desse trabalho seletivo e interpretativo, pois fornece métodos de investigação que possibilitam a construção de parâmetros analíticos do material produzido culturalmente, como afirma Martins:

[...] O tratamento científico das fontes faz encontrarem-se a cultura histórica presente no tempo passado e em seus vestígios e a cultura histórica presente no pesquisador e em seu meio cultural. As regras metódicas funcionam como convenções de garantia para que sejam evitadas a arbitrariedade de um subjetivismo incontrolado e a ilusão de uma objetividade absoluta (MARTINS, 2007, p.37).

O embate com toda a produção cultural historicamente concebida demanda dos seres humanos a criação de mecanismos de reflexão. Esse conteúdo cognitivo exige o desenvolvimento de habilidades e competências que permitam a seleção de informações, o exercício hermenêutico e a geração de perspectivas de orientação temporal.

O relacionamento entre as três dimensões da cultura histórica interfere diretamente no cotidiano dos seres humanos. O embate com suas prescrições é ponto pacífico. A elas pode-se aderir, refutar, rejeitar, transformar, revolucionar, entretanto, seu conteúdo, de uma forma ou de outra, influencia o agir humano. O entrelaçamento das dimensões estética, política e cognitiva pode gerar manipulação ideológica ou mesmo o relativismo moral e ético, mas também pode se apresentar em propostas de orientação temporal que comportem a concepção de um mundo no qual o respeito à dignidade humana, o acolhimento da diversidade e os princípios de liberdade e igualdade sejam universalmente vividos. Rüsen entende que essas dimensões da cultura histórica são universais, as chama de "constantes antropológicas" e, por isso, podem aproximar ou distanciar os seres humanos.

Nesse sentido, aberto está o espaço para o desenvimento de pesquisas no Brasil que visem discutir a relação entre a formação do pensamento histórico no âmbito escolar e sua aplicação prática no cotidiano vivido. Em outras palavras, temos a possibilidade de aprofundar nossas investigações a respeito do uso do 
raciocínio histórico, por parte dos estudantes, como meio de reflexão acerca das demandas da cultura histórica contemporânea. Certamente 0 encontro epistemológico entre a Didática da História e a Educação Histórica nos fornece uma série de possibilidades de reflexão, enquanto professores e pesquisadores do Ensino de História no Brasil, com vistas à construção de caminhos que qualifiquem a formação histórica escolar, tanto para discentes quanto para docentes, seja na educação básica, seja nos bancos das Universidades.

\section{Referências}

ABUD, K. M. Professores e a sua relação com o conhecimento na aula de História. In. BARCA, I. (Org.). Estudos de Consciência Histórica na Europa, América, Ásia e África. Actas das VII Jornadas Internacionais de Educação Histórica. Braga: Centro de Investigação em Educação - Instituto de Educação e Psicologia Universidade do Minho, 2008, p. 135-144.

ANGVIK. M.; BORRIES, B. V. Youth and History: a comparative European survey on historical and political attitudes among Adolescents. Hamburg: Korber Foundation, 1997.

ASHBY, R.; DICKINSON, A.; LEE, P. Project Chata: concepts of History and Teaching Approaches at key stages 2 and 3. In. Teaching History, 82, 1996, p. 630.

BARCA, I. Em torno da Epistemologia da História. In. BARCA, I.; GAGO, M. Questões de Epistemologia e Investigação em Ensino da História. Actas das III Jornadas Internacionais de Educação Histórica. Braga: Centro de Investigação em Educação/Instituto de Educação e Psicologia/Universidade do Minho, 2006, p. 17-25.

2000.

O Pensamento Histórico dos Jovens. Braga: Universidade do Minho,

DROYSEN, J. G. Arte e Método (1868). In. MARTINS, E. de R. M. (Org.). História pensada: teoria e método na historiografia europeia do Século XIX. Tradução de Pedro S. P. Caldas. São Paulo: Contexto, 2010, p. 31-46.

KOSELLECK, R. Futuro Passado: contribuição à semântica dos tempos históricos. Tradução de Wilma Patrícia Maas e Carlos Almeida Pereira; Revisão de César Benjamin. Rio de Janeiro: Contraponto \& Ed. PUC-Rio, 2006.

LEE, P. Progressão da compreensão dos alunos em História. In. BARCA, I. Perspectivas em Educação Histórica: actas das I Jornadas Internacionais de Educação Histórica. Braga: Centro de Investigação em Educação - Instituto de Educação e Psicologia - Universidade do Minho, 2001, p. 13-27. 
. Walking Backing into Tomorrow - Historical consciousness and understanding history. ('Caminhar para trás em direção ao amanhã' - a Consciência Histórica e o entender da História'). Trad.: José Norberto Soares. Comunicação apresentada no "Annual Meeting of American Educational Research Association, New Orleans, 2002" (Encontro Anual da Associação Americana de Pesquisa em Educação, New Orleans, 2002), p. 1-45. Disponível em http://centres.exeter.ac.uk/historyresource/journal7/lee.pdf. (Acesso em 12/04/2012).

MARTINS, E. de R. Cultura e Poder. 2 ed., São Paulo: Saraiva, 2007.

RÜSEN, J. Didática da História: passado, presente e perspectivas a partir do caso alemão. Tradução: Marco Roberto Kusnick. Revisão: Luis Fernando Cerri. In. SCHMIDT, M. A.; BARCA, I.; MARTINS, E. de R.; (Orgs.). Jörn Rüsen e o ensino de História. Curitiba: Editora UFPR, 2010, p. 23-40.

História Viva. Teoria da História III: formas e funções do conhecimento histórico. Tradução de Estevão de Rezende Martins. Brasília: Editora da Universidade de Brasília, 2007.

Historiografia Comparativa Intercultural. Tradução de Jurandir Malerba.

In: A História Escrita. São Paulo: Editora Contexto, 2006, p. 115-137.

Razão histórica. Teoria da história I: fundamentos da ciência histórica. Tradução de Estevão de Rezende Martins. Brasília: Editora Universidade de Brasília, 2001.

Recebido em 28 de junho de 2013.

Aprovado em 02 de agosto de 2013. 